\title{
Corrigendum: A role for Bicaudal-D2 in radial cerebellar granule cell migration
}

Dick Jaarsma, Robert van den Berg, Phebe S. Wulf, Susan van Erp, Nanda Keijzer, Max A. Schlager, Esther de Graaff, Chris I. De Zeeuw, R. Jeroen Pasterkamp, Anna Akhmanova \& Casper C. Hoogenraad

Nature Communications 5:3411 doi: 10.1038/ncomms4411 (2014); Published 11 Mar 2014; Updated 7 Jul 2014

The affiliation details for Susan van Erp are incorrect in this Article. The correct affiliation details for this author are given below:

Department of Translational Neuroscience, Brain Center Rudolf Magnus, University Medical Center Utrecht, 3584 CG Utrecht, The Netherlands. 